\title{
Development of Organization Theory of Library in Information Age-Team Organization
}

\author{
Peiwei Xue $\mathrm{e}^{1, \text { a }}$ \\ ${ }^{1}$ Huian County Library in Fujian Province, Quanzhou, 362100, China \\ ${ }^{\mathrm{a}}$ email
}

Keywords: Library, Organization theory, Team operation

\begin{abstract}
In the information age, the library of the essence of the work has been managed by internal resources to manage external huge information resources, which requires the library to establish efficient utilization of information resources, update the flexibility of quick response to user requirements and information organization. Information age team the organization form of the concrete can be used, because this kind of organization to focus and coordinate the resources of the library. Light of the defects in the current library organization model, this paper puts forward the function of the department, establish a team of librarians of the library organization mode and characteristics of library team organization model, advantages, and could face challenges are discussed. This paper points out that the library team organization model conforms to the new development trend of the library and its service.
\end{abstract}

\section{Current Traditional Models of Library Organization}

Library work should be carried out through the establishment of a suitable organizational model to support the operation, and whether the organizational model of the library is scientific and reasonable plays an important role in the development of the work. The traditional organizational model of a library is usually linear (also called function type), that is, each librarian is divided into departments that are divided according to the business attributes of the work. The core library matrix organization is still a strict hierarchical system, and did not completely change the functions of the pursuit of defects of internal management efficiency, still cannot play the whole concentrated library service, because in addition to service department, other departments and not to set up the service efficiency as the goal. There are contradictions in the long leadership, the membership is not clear; secondly, the performance evaluation of the project members cannot adopt the same standards and processes, and cannot effectively motivate the librarians and readers lack effective collection resources communication. The new library is user centric and actively carry out the service work, the essence of library from internal management resources to manage external huge information resources, which requires the library to establish the efficient use of elastic tissue to the needs of users and information update information resources, rapid response. The organizational goals of libraries are also changed from internal business management oriented to service oriented, which challenges the development of library service teams.

\section{Organization Concept and Department Division of Library Team}

Organization Concept. Team organization refers to the library information service in accordance with the scope of activities, to establish the overall organic cooperation, jointly completed information service as the core target, the various functions of the cross task team, this team is completely visible, to run the library based design organization is a complex task network and intelligent organization. In the team members to form the service target consensus, all work related tasks involved in the design team and knowledge to carry out individual complement each other, the internal management of self-management team members and self-control. The job of team managers is to guide, coordinate and create supportive organizational environments. It is the goal of team 
management to provide the whole service for users and create conditions for self-actualization of members.

Department Division. The whole library team is made up of two levels of team, one is to lead the team, and the other is the two kinds of task teams, which form the flat organization structure of two levels. Lead the team. A team of competent and competent curators with different abilities and experiences, who are responsible for making decisions about major issues, and thus forming a leadership team with a diversity of knowledge and skills. According to the size of the organization and management of the number of professional projects to determine the number of Museum leaders, generally two to three people. The operation principle of the leadership team can be summarized in four points: the members of mutual respect, each task, everyone has the final decision of the responsible for the affairs within the scope of the main library curators as leader and coordinator role, has the right to handle exceptions; in most cases, the important decisions without objection vote reach a settlement; keep good communication with leading members. Various task teams build around the center of library information services. The task force consists of multiple information service teams, equipment supply teams, application technology teams, human resource management and development teams that are divided into disciplines or service areas. Among them, each discipline or service field team is the core of the whole team work, other business team work around this core actively cooperate, carry out related business. The task teams maintain good lateral coordination and information communication through computer networks, intelligent technologies and other channels.

Compared with the former organizational model, library team organization has seven distinct characteristics. The whole organization has only one center, that is, to provide users with centralized and satisfactory information services by means of collective force. Cross functional and concurrent work among teams is a network organization of complex tasks. Therefore, team organization breaks the traditional hierarchical organization based on functional departments. People oriented management, team spirit as cohesive force. Emphasize the mutual respect, trust and cooperation among the members of the organization, make up each other in the work, and form a strong and positive sense of belonging and pride of team members. The organization management is characterized by the self-guidance and self-management of the members of the democratic management, and the close control and management of the traditional hierarchy organizations. The team responds to task flexibility. A team adapted to the needs of a service, added, withdrawn, or turned to new areas of development. Positions and positions are variable. Team members require a variety of skills, and thus positions vary depending on whether they have the ability to lead the team and whether it is appropriate for the new position. Computer network and intelligent technology as the basis for communication and exchange of information and work. It can be said that network and intelligent technology are the prerequisite for the organization of Library teams.

\section{Dynamic of Team Organization and "Pull" Systematic Service}

In real life, we have noticed that the lack of attention to customer service has made it difficult for libraries to face the fact that libraries provide a great deal of money to provide inferior services. The lack of effective user service is often not the result of a lack of professional interest in the individual. Managers and employees want to serve, and users end up sinking confidence, because libraries do not provide centralized, possible, and collective services. The library team operates a "pull" type of system service that draws services closer to user requirements rather than waiting for users. This requires the library to have adequate resources preparation and demand investigation. "Pull" service methods: services include all areas or a specific range of user needs; listen to user requirements; ask users to develop new products and research ideas; satisfy the users of high value-added, low cost information requirements. Therefore, "pull" service helps to improve service attitude, skills, values and organizational innovation ability. 


\section{Construction Principles of Library Team}

The purpose of forming a library team is to improve service efficiency and high performance team building. The consensus of the library team in twenty-first Century is to make progress in the development of digital libraries, to provide customer satisfaction services, to develop team spirit, to create community benefits, and to organize culture and so on. Transformational leadership. Fundamentally, the biggest task of team building is to study how to effectively and more authorize. As a whole planner, director, supporter and coordinator, the leader of library is responsible for the leadership, and the management mainly uses the power of knowledge, not the coercive power. Lead team meetings, ask team work progress and feedback, individual opinions and requests, and provide support. Many modern theories about the success of the team led by transformational leadership, leadership is not only for the employees' expectations and the conception of interest, but also actively play the role of expectations and ideas, learn how to make subordinates in a changing organization in a positive way. Effective team meetings; team consensus and constructive conclusions through democratic discussions are the source of team dynamics, from a single assessment incentive mechanism to a dual evaluation incentive mechanism. At present our country library commonly used single evaluation incentive mechanism, the performance of the individual as the basis for evaluation and reward. In the digital library, is the organic combination of various types of professional personnel to organize a team of high-quality customer service, therefore, is in fact the individual and the whole team to share the joy of success and failure to assume responsibility, must establish a dual evaluation incentive system. Library team organization is still in its initial stage of research. Team management is a direction of library management reform in the information age. It needs us to study and apply it deeply. It is not easy to change from traditional hierarchical organization to team organization. Librarians are confronted with the challenge of their traditional concepts of hierarchy and service, followed by the exploration of management practice.

\section{Human Resources Management and Performance Assessment}

Human resource is the most precious resource of organization. In certain organization form, human resource management is good or bad to decide whether an organization can effectively accomplish the task and organization goal. It includes job design, human resources planning, recruitment and selection, training and development, motivation, leadership, communication, performance evaluation, wages and salaries, labor relations, and Security Labor protection. The ultimate goal of human resource management is to achieve recruitment, training, stimulation and compensation. Any important decision made by any organization in the development and management of human resources needs to be linked with performance appraisal, and the selection system of energy level is adopted.

Table 1. Differences among MBO, BSC and KPI

\begin{tabular}{|c|c|c|c|}
\hline $\begin{array}{c}\text { Compared } \\
\text { method }\end{array}$ & $\begin{array}{c}\text { Management by } \\
\text { Objectives }\end{array}$ & Balanced Score Card & $\begin{array}{c}\text { Key Performance } \\
\text { Indicators }\end{array}$ \\
\hline Starting point & Objectives oriented & Balanced development & Grasp points \\
\hline $\begin{array}{c}\text { Applied } \\
\text { objects }\end{array}$ & All the staff & All the staff & All the staff \\
\hline Idea & Financial data & $\begin{array}{c}\text { Hierarchical } \\
\text { decomposition }\end{array}$ & top-down \\
\hline $\begin{array}{c}\text { Number of } \\
\text { indexes }\end{array}$ & $3 \sim 5$ & $10 \sim 15$ & moderate \\
\hline $\begin{array}{c}\text { Difficulty } \\
\text { degree }\end{array}$ & easy & difficult & Focus on key business \\
\hline Advantages & Clear direction & Excessively systematic & Incomprehensive work \\
\hline Disadvantages & Short-term behavior & & \\
\hline
\end{tabular}


Therefore, the performance appraisal is the core of human resources management, need to follow the following principles: the public principle of objectivity principle, feedback principle, the principle of difference, general principles, forward-looking principle and dynamic principle. At present, the most common methods of performance appraisal in human resource field are management by objectives (MBO), balanced score card (BSC), key performance indicator (KPI). Each of these methods has its own advantages and disadvantages, and needs to be chosen according to the actual situation. As shown in Table 1 below, we can see the differences between the methods. In actual performance management, one or more different methods can be flexibly chosen according to the actual situation, and cannot be generalized.

Performance appraisal is the most important part in human resource management. Many libraries still use four methods, such as morality, energy, diligence and performance, to assess the work performance of librarians, and ignore the monitoring of the performance implementation process. It is simple and extensive performance management, the performance of organizations and individuals lack of proper guidance, weakened the staff's work enthusiasm and the sense of belonging, and had a negative effect on the human resource management of the library.

The work of the library, like other enterprises and institutions, also requires the Librarians' initiative and creativity, while the initiative and creativity need a relaxed working atmosphere and a sound system guarantee. Therefore, the establishment of a scientific and comprehensive performance appraisal system, embassy staff in a fair and equitable environment to actively carry out information services.

\section{Closing Remarks}

With the deepening of library concept research and the rapid development of information technology, the demand of library users tends to be diversified and personalized. The existing mode of library organization has emerged trend to customer service demand backward. The team based library organization model can realize the complementary knowledge structure of team members, promote tacit knowledge exchange, develop team members' special skills and strengthen team service. It helps to improve the quality of librarians and improve the service quality, and realizes the construction of a three-dimensional, comprehensive, flexible and professional library service system.

\section{References}

[1] Lei Ping, Yang Jiayan, Wang Huisen, Application of Matrix Management Mode in Team Building of Reading Promotion in University Library [J]. Journal of Chengdu University of Technology (Social Sciences), 2015, 23 (6): 129-132.

[2] Gao Xiaoyan, Analysis on the Construction of Librarian Team of Prefectural \& Municipal - level Library in the Information Age [J]. Journal of Library and Information Science, 2010, 20(13): 59-61.

[3] Wang Zhonghua, Team Building and Performance Analysis of the New Media Service in Public Library [J]. Library Journal, 2016(7): 33-39.

[4] Xu Wenhui, Analysis on Countermeasures of Talent Team Construction for Public Libraries [J]. Jiangsu Science \& Technology Information, 2016(4): 47-48. 